\section{Partial trisomy for long arm of chromosome 16}

A congenitally abnormal female baby who survived for 8 days was found to have the kary'o yp $=46, X X,-9,+\operatorname{der}(9)$, $\mathrm{t}(9 ; 16)(\mathrm{p} 24 ; \mathrm{q} 13)$ pat (fig 1), that is, she was trisomic for the region $16 \mathrm{q} 13 \rightarrow 16 \mathrm{qter}$. The balanced translocation carried by the father appears to have arisen de novo, since his parents were karyotypically normal.

The baby, born at term, weighed $2780 \mathrm{~g}$. Abnormal features noted were: brachycephalic head; short neck with a very low hair line, webbing and a thick skin fold at the occiput; eyes with an antimongoloid slant with deep creases below them; malformed low set ears; micrognathia; cleft soft palate and high arched bony palate; fixed flexion deformities of all fingers, toes, hips, and knees (fig 2).

Necropsy findings included complete absence of the olfactory nerves with adherence of the cerebral hemispheres through an anterio-defect in the falx; the heart was larger than normal with a large atrial septal defect in the region of the foramen ovale; complete absence of the arch of the aorta, so that the pulmonary trunk continued onwards as the patent ductus to become a descending left sided aorta; there was a high interventricular septal defect with the aorta overriding this defect; the aorta gave rise to the innominate and right common carotid arteries but terminated with the origin of the latter vessel.

Trisomy 16 is the most common of the autosomal trisomic spontaneous abortions accounting for $28 \%$, suggesting that complete trisomy 16 is not compatible with live birth. Partial trisomy 16 is known in the liveborn,

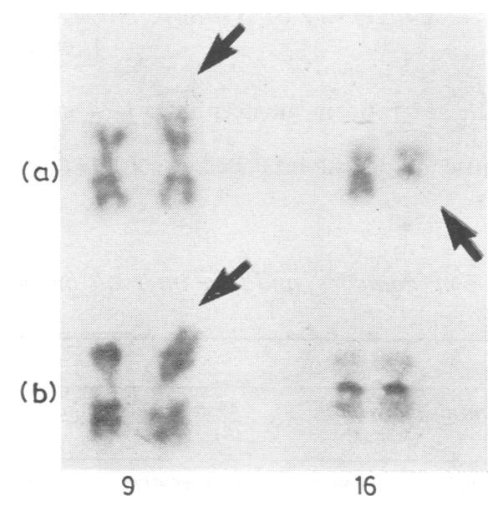

FIG $1 G$ banded particil karyotype of chromosomes 9 and 16 from (a) the proband's father, (b) the proband.

Received for publication 12 March 1981

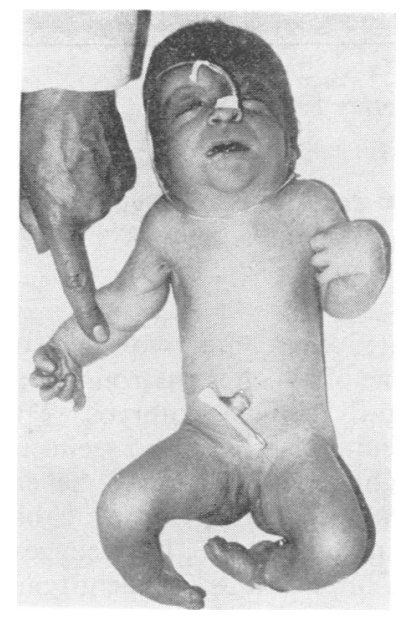

FIG 2 The proband.

but is not compatible with long term survival. ${ }^{2}{ }^{3}$ It has been postulated ${ }^{3}$ that trisomy $16 \mathrm{q}$ is mainly responsible for the total prenatal lethality of the full trisomy 16 . The very short survival of our case supports this.

If the chromosomes involved in the translocations with the chromosome 16 in the nine patients with partial trisomy $16 \mathrm{p}$ or $16 \mathrm{q}$ in two recent reviews ${ }^{23}$ and our own case are examined, three translocations involve chromosome 18. In the remaining seven patients, the other chromosome has a variable secondary constriction region $(9 \times 2, D \times 2, G \times 3)$ as has the chromosome 16 itself. There would appear not to be a random involvement of chromosomes.

K E Buckton AND D G D Barr MRC Clinical cind Population Cytogenetics Unit, Western General Hospital, and Royal Hospital for Sick Children, Sciennes Road, Edinburgh

\section{References}

1 Kajii T, Ferrier A, Nickawa N, Takahara H, Ohama K, Avirachan S. Anatomic and chromosomal anomalies in 639 spontaneous abortuses. Hum Genet 1980;55:87-98.

2 Roberts SH, Duckett DP. Trisomy $16 \mathrm{p}$ in a liveborn infant and a review of partial and full trisomy $16 . J \mathrm{Med}$ Genet 1978;15:375-81.

3 Garau A, Crisponi G, Peretti D, Vanni R, Zuffardi O. Trisomy 16q21-qter. Hum Genet 1980;53:165-7.

Requests for reprints to Ms K E Buckton, MRC Clinical and Population Cytogenetics Unit, Western General Hospital, Edinburgh EH4 2XU. 